\title{
BROADBAND WAVEGUIDE FEED FOR PARABOLIC REFLECTORS
}

\author{
P. BHUSHAN MITAL \\ Fellow Member I.E.T.E. (INDIA) \\ CR State College of Engineering, Murthal (Sonepat). India-131039 \\ (Received November 15, 1993; in final form January 4, 1994)
}

\begin{abstract}
The broadband requirement in microwave systems has necessitated attention on components that can operate over frequency ranges far broader than those of standard rectangular waveguides. This paper describes the design and development of an ridged horn to match the waveguide impedance to freespace impedance so that the horn could be used as a feed for an offset-fed parabolic reflector over a wide band of frequencies, i.e., $\mathrm{C}$ and $\mathrm{X}$ bands $(4.2$ to $10.2 \mathrm{GHZ})$. In the present case, a five stepped chebyshev transformer has been used. Complete design required for horn feed as well for the ridged waveguide components necessary for testing has been carried out. The results obtained are quite encouraging. Good agreement is found between the measured results and theoretical values.
\end{abstract}

\section{INTRODUCTION}

In a ridge waveguide, ridges on the top and bottom broadwalls of a waveguide cause a capacitive loading [1-10]. The electric lines of force tend to bunch up in the space between the ridges, as shown in Fig. 1. This effectively lowers the cutoff frequency for the odd modes in which the electric field is maximum at the center of the guide cross section having no effect on the even modes. It increases the bandwidth of a given waveguide in the direction of lower frequencies while maintaining the physical dimensions of the waveguide. The maximum bandwidth is limited by the closeness of the spacing between the ridges, which affects the power handling capability and mechanical tolerances on important dimensions.

Theoretical investigations show that the ridge waveguide gives wide bandwidths free from high mode interference. Frequency range of four to one $(4: 1)$ from the fundamental mode of operation are easily obtained with single and double ridge waveguides.

\section{(i) Calculation of Cutoff Wavelength ( $\left.\lambda_{c}^{\prime}\right)$ of Ridge Waveguide (TE $E_{10}$ mode)}

The cutoff condition of the waveguide corresponds to resonance of the equivalent lumped constant circuit as shown in Fig. 2, and the expression for the cutoff 


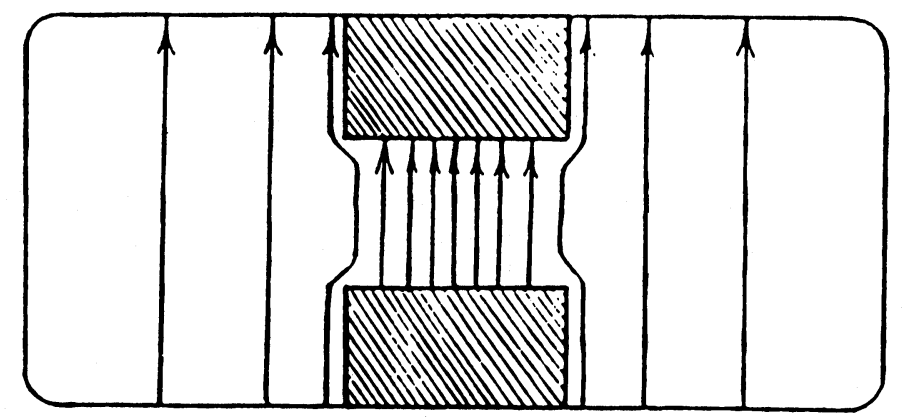

FIGURE 1

wavelength of the ridge waveguide is given as

$$
\frac{b_{1}}{b_{2}}=\frac{\cot \left[\left(1-\frac{a_{2}}{a_{1}}\right) \frac{\lambda c}{\lambda^{\prime} c} \frac{\pi}{2}\right]-\frac{2 C d}{\epsilon} \frac{b_{1}}{a_{1}} \frac{\lambda c}{\lambda^{\prime} c} \frac{\pi}{2}}{\tan \left(\frac{a_{2}}{a_{1}} \cdot \frac{\lambda c}{\lambda^{\prime} c} \frac{\pi}{2}\right)}
$$

This equation is solved for first order root to obtain the cutoff wavelength of the $\mathrm{TE}_{10}$ mode. The discontinuity capacitance, $\mathrm{Cd}$, is due to the fact that the ridges in

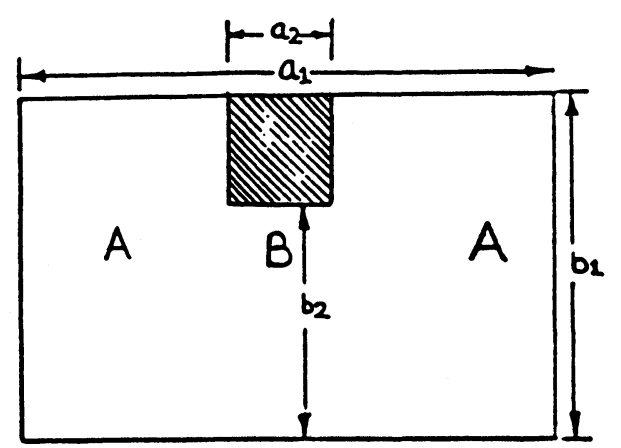

(a) Single Ridge Wave guide

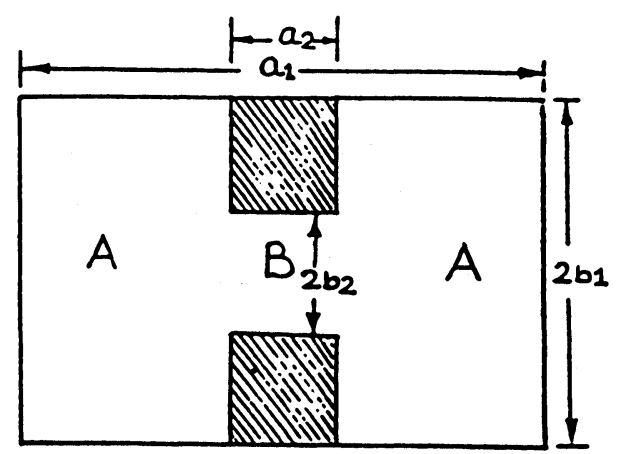

(b) Double Ridge Wave guide

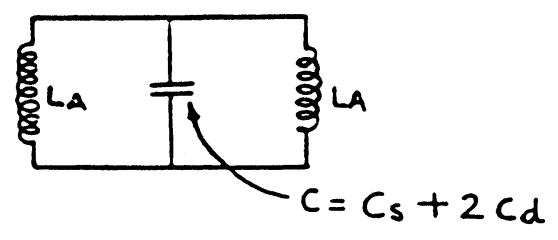

(C) Equivalent Lumped-Constant CKT

FIGURE 2 
the waveguide present discontinuities to the electromagnetic waves and cause local or higher order waves. The effect of these local fields are included in the calculation by the addition (at the proper location) of the discontinuity susceptance, which is capacitive in nature.

The discontinuity capacitance, $\mathrm{Cd}$, is obtained by means of Schwarz-christoffel transformation as

$\frac{2 \mathrm{Cd}}{\epsilon}=\frac{2}{\pi}\left[\frac{\chi^{2}+1}{\chi} \cosh ^{-1}\left(\frac{1+\chi^{2}}{1-\chi^{2}}\right)-2 \ln \frac{4 \chi}{1-\chi^{2}}\right]$

where $\chi=\frac{b_{2}}{b_{1}}=\frac{d}{b}$

(ii) Calculation of Characteristic Impedance $\left(\mathrm{Zo}_{\infty}\right)$

The characteristic impedance of the ridge waveguide at the infinite frequency is calculated from the expression given below.

$$
\begin{aligned}
\mathrm{Yo}_{x} & =2 \sqrt{\frac{\epsilon_{0}}{\mu_{0}}} \frac{\lambda^{\prime} \mathrm{c}}{2 \pi \mathrm{d}}\left\{\frac{2 \mathrm{~d}}{\lambda^{\prime} \mathrm{c}} \cos ^{2}\left(\frac{\pi \mathrm{S}}{\lambda^{\prime} \mathrm{c}}\right) \ln \mathrm{CSC}\left(\frac{\pi \mathrm{d}}{2 \mathrm{~b}}\right)+\frac{\pi \mathrm{S}}{2 \lambda^{\prime} \mathrm{c}}\right. \\
& \left.+\frac{1}{4} \sin \left(\frac{2 \pi \mathrm{S}}{\lambda^{\prime} \mathrm{c}}\right)+\frac{\mathrm{d}}{\mathrm{b}} \frac{\cos ^{2}\left(\frac{\pi \mathrm{S}}{\lambda^{\prime} \mathrm{c}}\right)}{\sin ^{2}\left(\frac{\pi}{\lambda^{\prime} \mathrm{c}}(\mathrm{a}-\mathrm{S})\right)}\left[\frac{\pi(\mathrm{a}-\mathrm{S})}{2 \lambda^{\prime} \mathrm{c}}-\frac{1}{4} \sin \left(\frac{2 \pi(\mathrm{a}-\mathrm{S})}{\lambda^{\prime} \mathrm{c}}\right)\right]\right\}
\end{aligned}
$$

and $\mathrm{Zo}_{x}=\frac{1}{\mathrm{yo}_{\infty}}, \sqrt{\frac{\mu_{0}}{\epsilon_{0}}}=12 \mathrm{o} \pi$

$\mathrm{a}=$ width of waveguide

$\mathrm{b}=$ height of waveguide

$\mathrm{S}=$ width of ridge

$\mathrm{d}=$ height of ridge

$\lambda^{\prime} \mathrm{c}=$ cutoff wavelength of ridge waveguide for $\mathrm{TE}_{10}$ mode

The detailed derivation of this relation is given in Appendix I.

The values of $2 \mathrm{~cd} / \epsilon$, cutoff wavelength $\lambda^{\prime} \mathrm{c} / \lambda \mathrm{c}$, and characteristic impedances thus obtained at infinite frequency for different step ratios are summarised in Table I.

\section{DESIGN AND FABRICATION OF HORN FEED}

In a chebyshev transformer, there are stepped impedance sections proportioned to chebyshev polynomials that result in better broadband results for a given length and bandwidth than the use of tapers or binomial step functions. 
TABLE I

\begin{tabular}{lllll}
\hline & Impedance & $\mathrm{d} / \mathrm{b}$ ratio & $\frac{2 C_{\mathrm{d}}}{\mathrm{e}}$ & $\frac{\lambda_{\mathrm{c}}^{\prime}}{\lambda_{\mathrm{c}}}$ \\
\hline Ridge waveguide & $274 \mathrm{ohms}$ & .6596 & .2318948 & 1.1640 \\
Step No. 1 & $285.55 \mathrm{ohms}$ & .6917 & .1919330 & 1.1413 \\
Step No. 2 & $307.30 \mathrm{ohms}$ & .7536 & .1260418 & 1.1024 \\
Step No. 3 & $336.15 \mathrm{ohms}$ & .8930 & .0551191 & 1.0562 \\
Step No. 4 & $361.75 \mathrm{ohms}$ & .9366 & .0107073 & 1.0189 \\
Step No. 5 & 377 ohms & 1 & 0 & 1 \\
\hline
\end{tabular}

The structure consists of a symmetrical series of steps on the top and bottom of the inside of the waveguide walls with approximately quarter wavelength spacing between steps. Each section has a constant impedance throughout its length, i.e., from one end of the section to the other end. Transition is made with smooth tapers in the outside dimensions and in the width of the ridges, thereby maintaining a constant ratio of ridge width to guide width (s/a ratio) throughout the length of the transformer.

The number of steps required for a given maximum VSWR are calculated from the equation given below.

$\operatorname{Smax}=1+\frac{\ln \left[\frac{Z_{n}+1}{Z_{1}}\right]}{T_{n-1}\left[\frac{1}{\cos \phi_{1}}\right]}$

Where Smax $=$ Maximum voltage standing wave ratio

$\mathrm{Z}_{1}$ and $\mathrm{Z}_{\mathrm{n}}+1$ are the terminating characteristic impedances

$\phi$ is the electrical spacing of the steps at the low frequency end of the band.

The ratios of the reflection coefficients of the steps must equal the ratios of a set of constants 'am', i.e.,

$r_{1}: r_{2}: r_{3} \ldots r_{n}=a_{1}: a_{2}: a_{3} \ldots a_{n}$

According to Hansen

$\mathrm{rm}=2 \ln \left[\frac{\mathrm{Z}_{\mathrm{m}}+1}{\mathrm{Z}_{\mathrm{m}}}\right]$

Hence, step ratios are given by

$\ln \frac{Z_{2}}{Z_{1}}: \ln \frac{Z_{3}}{Z_{2}}: \ldots \ln \frac{Z_{n}+1}{Z_{n}}=a_{1}: a_{2}: a_{3} \ldots a_{n}$. 
The ratio at a given step may be computed in terms of the terminating impedances and the 'am' values by

$\ln \frac{Z_{m}+1}{Z_{m}}=\frac{a m \ln \frac{Z_{n}+1}{Z_{1}}}{a_{1}+a_{2}+\cdots+a_{n}}$

Once the number of steps has been chosen, the chebyshev coefficients and the resulting characteristic impedances required for each section are calculated along with $d / b$ ratios. As the $d / b$ ratio is constant for the given step of the transformer, the step discontinuity capacitance $2 C_{\mathrm{d}} / \epsilon$ AND $\lambda \mathrm{c}^{\prime} / \lambda \mathrm{c}$ are calculated and the values are given in Table I.

Calculation of the length required for each section is than undertaken. Since the $\mathrm{a}$ and $\mathrm{b}$ dimensions vary according to the outside tapers, the cutoff characteristics vary throughout the length of each section, thereby introducing varying $\lambda \mathrm{g}$ values. To overcome this problem, the $\mathrm{TE}_{10}$ mode cutoff frequencies are determined for both ends of each section. The mean $\lambda \mathrm{g}$ at each and of the section under consideration is than calculated as follows

$\lambda \mathrm{gm} 21=\frac{2 \lambda \mathrm{g} 21 \mathrm{~L} \cdot \lambda \mathrm{g} 21 \mathrm{H}}{(\lambda \mathrm{g} 21 \mathrm{~L}+\lambda \mathrm{g} 21 \mathrm{H})}$

$\lambda \mathrm{gm} 22=\frac{2 \lambda \mathrm{g} 22 \mathrm{~L} \lambda \mathrm{g} 22 \mathrm{H}}{(\lambda \mathrm{g} 22 \mathrm{~L}+\lambda \mathrm{g} 22 \mathrm{H})}$

where $\lambda \operatorname{gm} 21=$ Mean at small end of the section

$\lambda \operatorname{gm} 22=$ Mean at big end of the section.

$\lambda \mathrm{g} 21 \mathrm{~L}=$ Guide wavelength at small end of section at low frequency end.

$\lambda \mathrm{g} 21 \mathrm{H}=$ Guide wavelength at small end of section at high frequency end

$\lambda \mathrm{g} 22 \mathrm{~L}=$ Guide wavelength at big end of section at low frequency end.

$\lambda \mathrm{g} 22 \mathrm{H}=$ Guide wavelength at big end of section at high frequency end.

The actual length of the section(s) is found from the relation given below

$S=\frac{\lambda g m 21 \lambda \operatorname{gm} 22}{2(\lambda \operatorname{gm} 21+\lambda \operatorname{gm} 22)}$

The detailed dimensions of the ridged horn are shown in Fig 3.

\section{PERFORMANCE AND EVALUATION}

Based on the design given in Part-II, a horn feed unit was fabricated locally from aluminum material and its performance assessed. The experimental setup for VSWR measurements is shown in Fig. 4. An EC sweep generator Model UM 400 has been used as a microwave signal source. The desired frequency range is obtained 


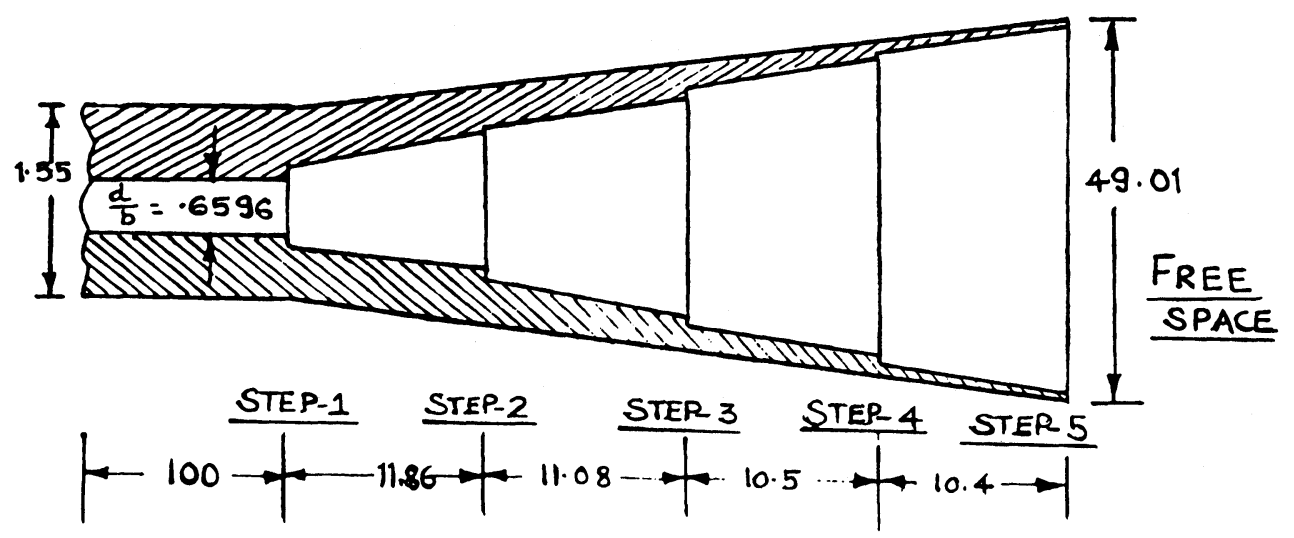

FIGURE 3

from its RF-plug in units CA-400 and XA-400. A locally fabricated attenuator is also included in the circuit. A probe is moved in the slot provided in a section of double ridge wave guide to sample the voltage.

The output of the probe is detected and read on a VSWR meter. The probe entering in the slotted section is a discontinuity and, to avoid this, the penetration depth is kept as small as possible. For low VSWR, this is not a problem but for higher values, the probe must be inserted deeper to read the minimum. The slot width is also kept vary small, i.e., $16 \%$ of the total ridge width. Values of the VSWRs obtained at different frequencies are tabulated in Table II. E \& H plane radiation patterns obtained at $4.2 \mathrm{GHz}, 7.0 \mathrm{GHz}$ and $10.2 \mathrm{GHz}$ are shown in Fig. 5,6 and 7.

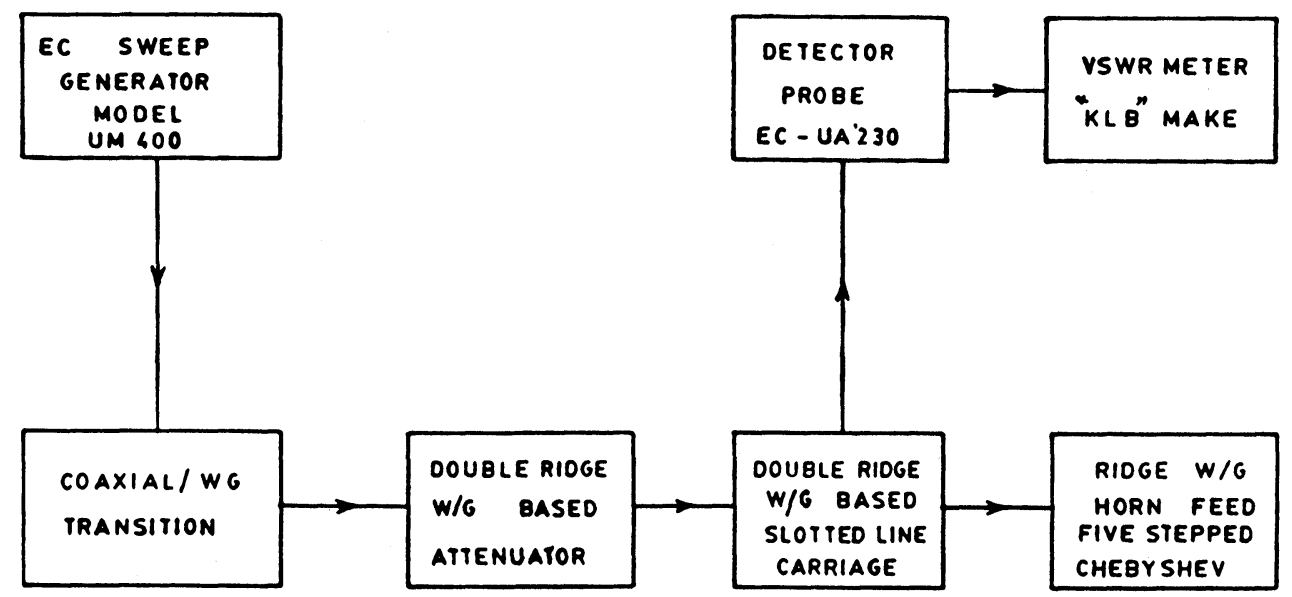

FIGURE 4 Experimental setup for measurement of VSWR. 
TABLE II

\begin{tabular}{ccc}
\hline Sr. No. & Frequency in $\mathrm{GHz}$ & VSWR \\
\hline 1. & 4.2 & 1.4 \\
2. & 4.8 & 1.4 \\
3. & 5.2 & 1.3 \\
4. & 5.8 & 1.3 \\
5. & 6.2 & 1.3 \\
6. & 6.8 & 1.2 \\
7. & 7.0 & 1.2 \\
8. & 7.5 & 1.2 \\
9. & 8.0 & 1.2 \\
10. & 8.5 & 1.1 \\
11. & 9.0 & 1.2 \\
12. & 9.5 & 1.2 \\
13. & 10.0 & 1.2 \\
14. & 10.2 & 1.3 \\
\hline
\end{tabular}

\section{SUMMARY AND CONCLUSION}

Despite the simplifying assumptions and small errors in the design method, the unit exhibited the typical chebyshev ripple response, but the ripple varied between VSWR of approximately 1.1 to 1.4 over the frequency range $4.2 \mathrm{GHz}$ to $10.2 \mathrm{GHz}$. From the radiation pattern at $7.0 \mathrm{GHz}$, it is seen that beam width at $3 \mathrm{db}$ is $6^{\circ}$ and at $10 \mathrm{db}$ is $24^{\circ}$. The cross-polarized component is approximately $20 \mathrm{db}$ down. Mechanical tolerances presented some problems in the fabrication. In general, it

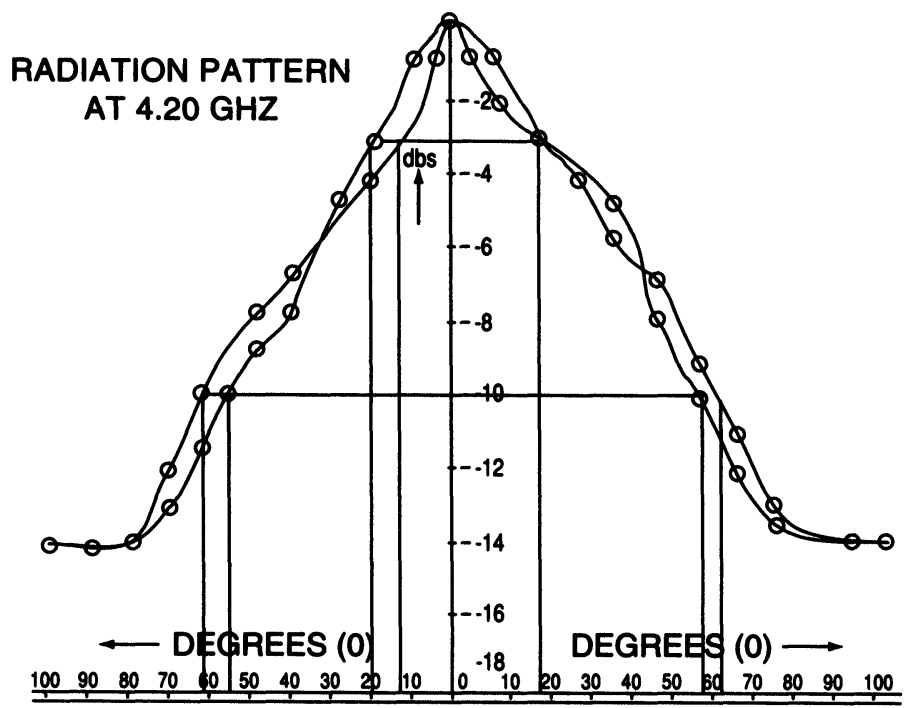

FIGURE 5 


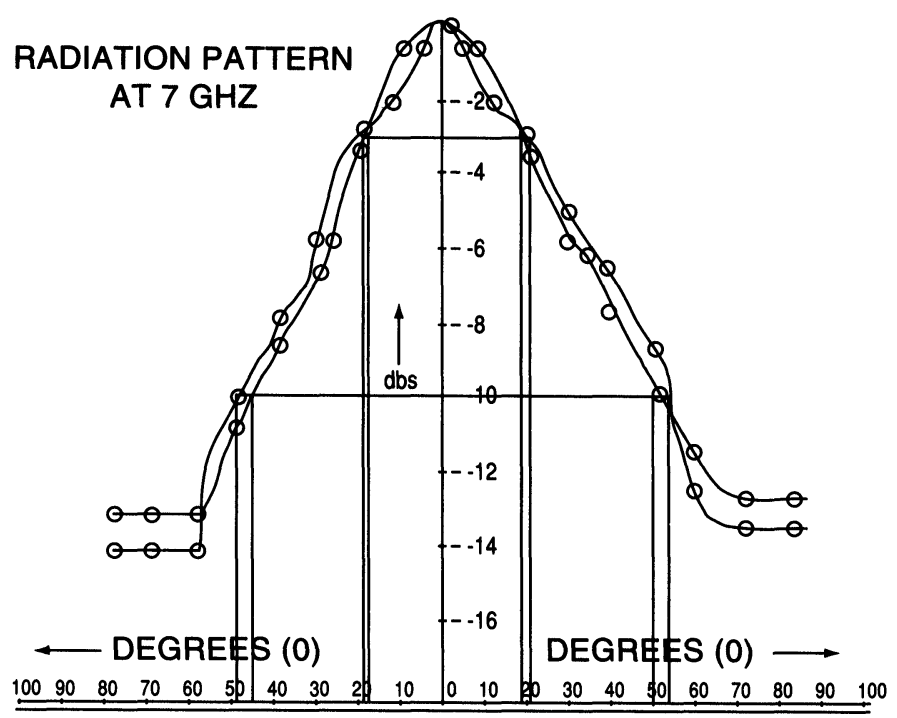

FIGURE 6

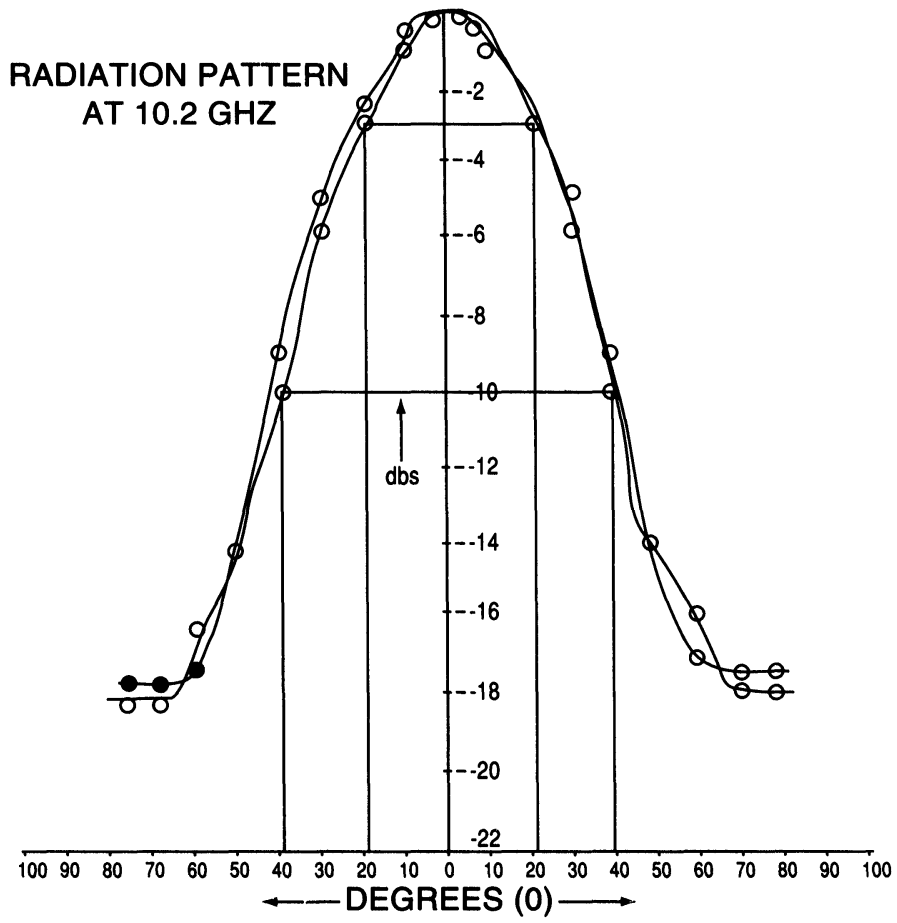

FIGURE 7 
was found that the distance between steps was relatively uncritical but the height of the steps proved to be quite critical. Tolerances of the order of $\pm 0.004^{\prime \prime}$ were found to be adequate for the section length but changes as small as 0.0015 inch in the step heights introduced measurable differences in the VSWR patterns. This being the first experimental model, the results, although not absolutely perfect, are still considered encouraging.

\section{REFERENCES}

1. S.B. Cohn, Properties of Ridge Waveguide, Proc. I.R.E., Aug. 1947, 783-788.

2. Peter Lubell, Design Innovation Using Double-Ridge Waveguide.

3. T. Anderson, Standardization of Ridged Waveguides, Microwave Journal, April 1961, 74-78.

4. T.S. Chen, Calculation of the Parameters of Ridge Waveguides. I.RE Trans M.T.T., Jan. 1957, 12-17.

5. S.B. Cohn, Optimum Design of Stepped Transmission Line Transformers, I.RE. Trans. MTT., April 1955.

6. Hensperger, Broadband Stepper Transformer from Rectangular to Double Ridge Waveguide, IRF. Trans. MTT., July 1958, 311-314.

7. R.E. Collin, The Optimum Tapered Transmission Line Matching Section, Proc. IRE., April 1956, 539-548.

8. S.B. Cohn, Design of Simple Broadband Waveguide to Coaxial Line Junctions, Proc. IRE., Sept. 1947, 920-926.

9. Walton Sundberg, Broadband Ridged Horn Design, Microwave Journal, March 1964, 96-101.

10. S.A. Schelkunoff, Electromagnetic Waves, Von Nostrand, 1943, 494-496.

\section{APPENDIX I}

\section{DERIVATION OF EXPRESSION FOR THE CHARACTERISTIC IMPEDANCE OF RIDGE WAVEGUIDE}

The average power carried by the ridge waveguide is given by

$$
\begin{aligned}
\mathrm{P}= & \sqrt{\frac{\epsilon_{0}}{\mu_{0}}} \frac{\lambda}{\lambda \mathrm{g}} \frac{\mathrm{E}_{0}^{2}}{2 \pi} \beta \frac{\lambda \mathrm{c}^{2}}{\mathrm{k}}\left\{\mathrm{m} \frac{2 \beta}{\mathrm{k}} \cos ^{2} \frac{\pi \gamma}{\mathrm{k}} \ln \mathrm{CSC} \frac{\pi \mathrm{d}}{2 \mathrm{~b}}+\frac{\pi \nu}{2 \mathrm{k}}\right. \\
& \left.+\frac{1}{4} \sin 2 \pi \frac{\nu}{\mathrm{k}}+\frac{\mathrm{d}}{\mathrm{b}} \frac{\cos ^{2} \pi \nu / \mathrm{k}}{\sin ^{2} \frac{2 \pi \delta}{\mathrm{k}}}\left[\frac{\pi \delta}{\mathrm{k}}-\frac{1}{4} \sin 4 \pi \frac{\delta}{\mathrm{k}}\right]\right\} \\
= & \sqrt{\frac{\epsilon_{0}}{\mu_{0}}} \frac{\lambda}{\lambda \mathrm{g}} \frac{\mathrm{E}_{0}^{2}}{2 \pi} \beta \frac{\lambda \mathrm{c}^{2}}{\mathrm{k}}\{\mathrm{A}\}
\end{aligned}
$$

where $E_{0}=$ Electric field intensity $=\frac{V_{0}}{d}$ at the center of the ridged gap

$\mathrm{V}_{0}=$ Instant peak voltage across the center of the guide

$\mathrm{d}=$ ridged gap height

$\mathrm{m}=1$ for double ridge waveguide

$=2$ for single ridge waveguide 
$\alpha=\frac{\mathrm{b}}{\mathrm{a}} \nu=\frac{\mathrm{s}}{\mathrm{a}} \mathrm{k}=\frac{\lambda \mathrm{c}}{\mathrm{a}} \beta=\frac{\mathrm{d}}{\mathrm{a}} \delta=\frac{1-\mathrm{s} / \mathrm{a}}{2} \mathrm{p}=\frac{\lambda \mathrm{c}}{\lambda}$

$\frac{\beta}{\mathrm{k}}=\frac{\mathrm{d} / \mathrm{a}}{\lambda \mathrm{c} / \mathrm{a}}=\frac{\mathrm{d}}{\lambda \mathrm{c}} \frac{\nu}{\mathrm{k}}=\frac{\mathrm{s} / \mathrm{a}}{\lambda \mathrm{c} / \mathrm{a}}=\frac{\mathrm{s}}{\lambda \mathrm{c}}$

$\frac{\delta}{\mathrm{k}}=\frac{\frac{\mathrm{a}-\mathrm{s}}{2 \mathrm{a}}}{\lambda \mathrm{c} / \mathrm{a}}=\frac{\mathrm{a}-\mathrm{s}}{2 \lambda \mathrm{c}}$

The ridge guide impedance is defined as

$Z_{0}=\frac{V_{0}^{2}}{2 p}=\frac{E_{0}^{2} d^{2}}{2 p}$

$Y_{0}=\frac{1}{Z_{0}}=\frac{2 p}{E_{0}^{2} d^{2}}=\frac{2}{d^{2}} \frac{p}{E_{0}^{2}}$

Putting the value of $P$ from eqn (1), we get

$$
\begin{aligned}
\mathrm{Y}_{0} & =\frac{2}{\mathrm{~d}^{2}} \frac{1}{\mathrm{E}_{0}^{2}} \sqrt{\frac{\mu_{0}}{\epsilon_{0}}} \frac{\lambda}{\lambda \mathrm{g}} \frac{1}{2 \pi} \mathrm{E}_{0}^{2} \frac{\mathrm{d}}{\lambda \mathrm{c}} \cdot \lambda \mathrm{c}^{2}\{\mathrm{~A}\} \\
& =2 \sqrt{\frac{\epsilon_{0}}{\mu_{0}}} \frac{\lambda}{\lambda \mathrm{g}} \frac{\lambda \mathrm{c}}{2 \pi \mathrm{d}}\{\mathrm{A}\}
\end{aligned}
$$

At infinite frequency $\lambda=\lambda \mathrm{g}$

$$
\begin{aligned}
\mathrm{Y}_{0 \infty 0}= & 2 \sqrt{\frac{\epsilon_{0}}{\mu_{0}}} \frac{\lambda \mathrm{c}^{\prime}}{2 \pi \mathrm{d}}\{\mathrm{A}\} \\
= & 2 \sqrt{\frac{\epsilon_{0}}{\mu_{0}}} \frac{\lambda \mathrm{c}^{\prime}}{2 \pi \mathrm{d}}\left\{\frac{2 \mathrm{~d}}{\lambda^{\prime} \mathrm{c}} \cos ^{2}\left(\frac{\pi \mathrm{s}}{\lambda^{\prime} \mathrm{c}}\right) \ln \csc \frac{\pi \mathrm{d}}{2 \mathrm{~b}}+\frac{\pi \mathrm{s}}{2 \lambda^{\prime} \mathrm{c}}+\frac{1}{4} \sin \left(\frac{2 \pi \mathrm{s}}{\lambda^{\prime} \mathrm{c}}\right)\right. \\
& +\frac{\mathrm{d}}{\mathrm{b}} \frac{\cos ^{2} \pi \mathrm{s} / \lambda^{\prime} \mathrm{c}}{\sin ^{2}\left[\frac{\pi(\mathrm{a}-\mathrm{s})}{\lambda^{\prime} \mathrm{c}}\right]}\left[\frac{\pi(\mathrm{a}-\mathrm{s})}{2 \lambda^{\prime} \mathrm{c}}-\frac{1}{4} \sin \left(\frac{2 \pi(\mathrm{a}-\mathrm{s})}{\lambda^{\prime} \mathrm{c}}\right]\right\}
\end{aligned}
$$

This is the required expression for ridge waveguide admittance at infinite frequency on pv concept. The characteristic impedance at any other frequency $f$ can be calculated from the relation

$$
\mathrm{Z}_{0}=\frac{\mathrm{Z}_{000}}{\sqrt{1-\left(\frac{\mathrm{fc}}{\mathrm{f}}\right)^{2}}}
$$


We can verify the characteristic impedance of ordinary waveguide (without ridges) from the above formula given by eqn (5) as follows.

Case I No ridges i.e. $d=b, s=0.2 a$

$\operatorname{Cosec} \frac{\pi \mathrm{d}}{\mathrm{db}}=\operatorname{cosec} \pi / 2=1$

$$
\begin{aligned}
Y_{100} & =\frac{2}{377} \frac{2 a}{2 \pi d}\left\{\frac{d}{b} \times \frac{1}{1} \times\left[\frac{\pi a}{2 \times 2 a}-\frac{1}{4} \sin \frac{2 \pi a}{2 a}\right\}\right. \\
& =\frac{2}{377} \frac{2 a}{2 \pi d} \frac{\pi}{2 \times 2}=\frac{a}{377 \times 2 b}
\end{aligned}
$$

$\therefore Z_{100}=377 \times \frac{2 b}{a}$

Case II $d=b, s=a$

$$
\begin{aligned}
\mathrm{Y}_{100} & =\frac{2}{377} \frac{2 \mathrm{a}}{2 \pi \mathrm{b}}\left\{0+\frac{\pi}{2} \frac{\mathrm{a}}{2 \mathrm{a}}+0+1[0-0]\right\} \\
& =\frac{2}{377} \frac{\mathrm{a}}{\pi \mathrm{b}} \frac{\pi}{4}=\frac{\mathrm{a}}{377 \times 2 \mathrm{~b}} \\
\therefore \mathrm{Z}_{100} & =377 \times \frac{2 \mathrm{~b}}{\mathrm{a}}
\end{aligned}
$$



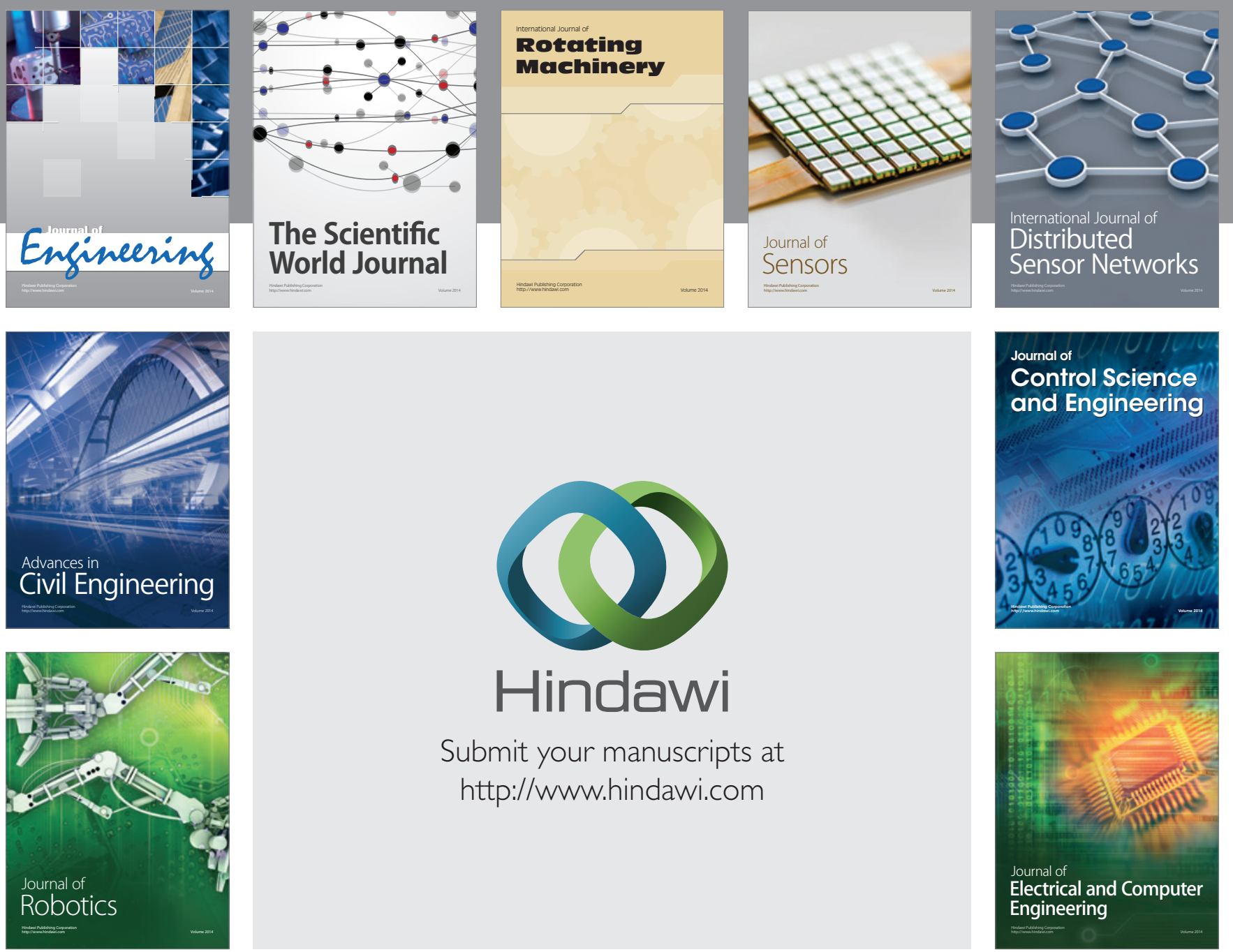

Submit your manuscripts at

http://www.hindawi.com
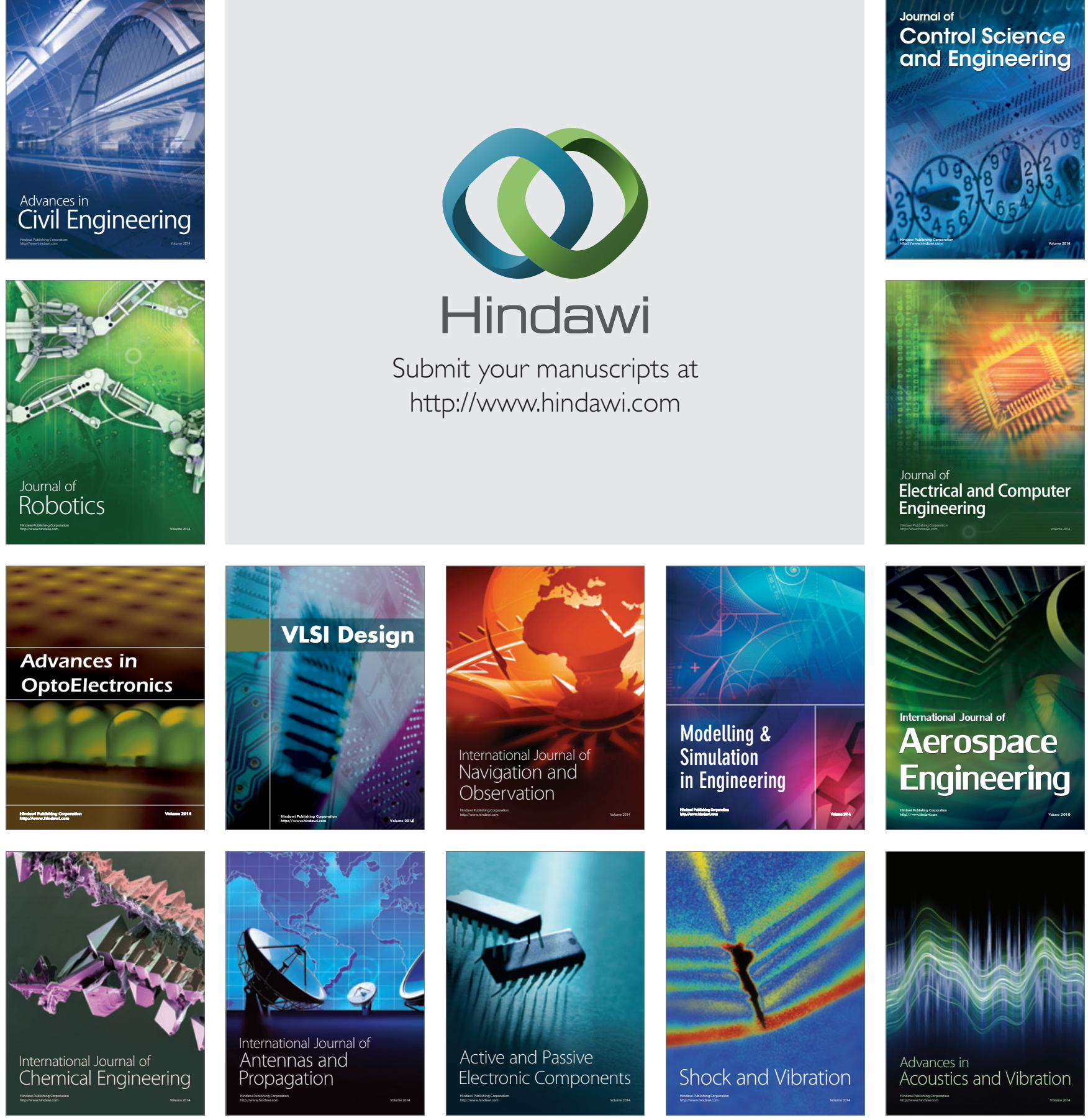